\title{
Valor nutritivo de pastagens consorciadas com diferentes espécies de leguminosas
}

\author{
Clair Jorge Olivo ${ }^{1}$, Magnos Fernando Ziech², Gilmar Roberto Meinerz², Carlos Alberto \\ Agnolin ${ }^{2}$, Denize Tyska², José Francisco Both ${ }^{2}$
}

\footnotetext{
${ }^{1}$ Departamento de Zootecnia - Universidade Federal de Santa Maria, Campus Camobi, CEP: 97105-900, Santa Maria, RS.

2 Curso de Zootecnia da UFSM, RS - Brasil.
}

\begin{abstract}
RESUMO - O objetivo neste trabalho foi avaliar o valor nutritivo de dois sistemas forrageiros (SF): capim-elefante (CE) + azevém + trevo-branco + espécies de crescimento espontâneo (SF1); e capim-elefante + azevém + amendoim forrageiro + espécies de crescimento espontâneo (SF2). O delineamento experimental utilizado foi de blocos ao acaso com duas repetições (piquetes), totalizando quatro piquetes de 0,25 ha. O capim-elefante foi estabelecido em linhas espaçadas a cada $4 \mathrm{~m}$ e as pastagens foram adubadas com 50-40-40 kg/ha do formulado NPK. Durante o período experimental, foram realizados nove pastejos (326 dias no SF1 e 336 dias no SF2). Para avaliação, foram usadas vacas em lactação da raça Holandesa, recebendo suplementação alimentar de concentrado (3,5 kg/dia). Avaliaram-se a massa de forragem inicial, a composição botânica e os componentes estruturais do capim-elefante. Amostras de simulação de pastejo foram coletadas para análises dos teores de fibra em detergente neutro (FDN) e proteína bruta (PB), da digestibilidade in vitro da matéria seca (DIVMS) e matéria orgânica (DIVMO) e da composição em nutrientes digestíveis totais (NDT). No sistema forrageiro com trevo-branco, os valores médios de FDN foram de 47,71\%; os de PB, 15,69\%; a DIVMS, 77,28\%; a DIVMO, 75,92\%; e o teor de NDT, 65,00\%, enquanto, no sistema com amendoim forrageiro, foram de 51,84; 14,62; 73,7; 72,27; e 63,06\%, respectivamente. Os resultados de PB, DIVMS e DIVMO na pastagem total foram melhores no sistema forrageiro com trevo-branco, enquanto os de FDN foram melhores no sistema com amendoim forrageiro. O valor nutritivo das duas pastagens é melhor no período hibernal. Considerando a adubação, o manejo e o tempo de utilização da pastagem, pode-se afirmar que os valores qualitativos de ambos os sistemas são elevados.
\end{abstract}

Palavras-chave: amendoim forrageiro, azevém, capim-elefante, trevo-branco

\section{Nutritive value of mixed pastures with different legumes species}

\begin{abstract}
The objective of this study was to evaluate the nutritive value of two pasture-based systems (PS), with elephant grass $(E G)$ + ryegrass (RG) + white clover (WC) + spontaneous growing species (SGS), for PS1; and EG + RG + forage peanut (FP) + SGS, for PS2. Four paddocks, each one with 0.25 ha, were used in the assessment. A complete randomized block design was used with two replications (paddocks). The EG was established in rows with $4 \mathrm{~m}$ spacing. Pastures were fertilized with 50-40-40 kg/ha NPK formulated, respectively. Nine grazings were performed during the experimental period (326 days in PS1 and 336 in PS2). Holstein cows receiving $3.5 \mathrm{~kg} /$ daily complementary concentrate feed were used in the evaluation. The initial forage mass, botanical composition and structural components of EG were evaluated. Samples were collected by the hand-plucking method to analyze neutral detergent fiber (NDF), crude protein (CP), in vitro dry matter digestibility (IVDMD), in vitro organic matter digestibility (IVOMD) and total nutrient digestibility (TND). The mean values for NDF, CP, IVDMD, IVOMD and TDN were 47.71; 15.69; 77.28; 75.92; 65.00\% in PS1; and 51.84; 14.62; 73.72; 72.27 and 63.06\% in PS2, respectively. Superior results were detected for CP, IVDMD, IVOMD and TDN forage total in PS1 while superior NDF values were detected in PS2. In two pastures, the best nutritive value results were observed in the winter period. Both systems showed high qualitative values considering fertilization, management and use time.
\end{abstract}

Key Words: elephant grass, forage peanut, ryegrass, white clover

\section{Introdução}

Entre as vantagens da utilização de pastagens na produção de herbívoros, destaca-se o baixo custo, uma vez que a colheita da forragem é feita pelo próprio animal, transformando proteína vegetal em proteína animal, de maior valor biológico. Contudo, isso só é possível se o manejo da pastagem possibilitar a manutenção de seu 
potencial produtivo, respeitando as exigências nutricionais dos animais (Hodgson, 1990).

As pastagens, no início de seu desenvolvimento, apresentam máxima qualidade e baixo acúmulo de forragem. À medida que segue seu desenvolvimento, perdem qualidade pela redução de sua digestibilidade, mesmo apresentando aumento de produção de forragem. Dessa forma, o manejo racional da pastagem deve visar à manutenção de uma situação intermediária, otimizando sua qualidade e produtividade (Blaser, 1982).

Em grande parte das propriedades leiteiras, as pastagens são a principal fonte de volumoso para vacas em lactação. Nesse contexto, espécies perenes, como o capim-elefante, têm papel importante, por suas características produtivas e de adaptação às regiões e à perenidade.

Na maioria das propriedades que utilizam essa forrageira, o cultivo é feito na forma exclusiva e a adubação é realizada com fertilizantes químicos, especialmente com altas doses de nitrogênio (Olivo et al., 2006). Essa estratégia de utilização intensiva da pastagem pode contribuir para redução de sua produtividade e perenidade no decorrer dos anos (Dall’'Agnol et al., 2004; Lima et al., 2004).

Nas pesquisas existentes, no entanto, o capim-elefante é avaliado especialmente no período estival, notadamente no ápice de sua produção, entre o final da primavera e o verão. Existem poucas pesquisas que avaliam essa forrageira no decorrer do ano agrícola (Olivo et al., 2006) ou com associação dessa cultura com outras espécies visando à constituição de sistemas forrageiros (Sobczak et al., 2005). Essas consorciações, especialmente com leguminosas, podem contribuir para melhoria dos recursos envolvidos, além de possibilitar maior equilíbrio na dieta dos animais durante o ano (Vidor \& Jacques, 1998; Real, 2002; Santos et al., 2002).

Estudos comprovam superioridade das misturas forrageiras no desempenho animal, principalmente pela alta digestibilidade e altas concentrações de nitrogênio das leguminosas, que aumentam a capacidade de suporte das pastagens e permitem maior ganho por unidade de área (Quadros \& Maraschin, 1987). Além disso, o consórcio de gramíneas com leguminosas possibilita o aumento do período de pastejo, resultando em melhor rendimento animal (Assmann et al., 2004).

Espécies como azevém, trevo-branco e amendoim forrageiro, por possuírem alto valor nutritivo (Paim \& Riboldi, 1994; Ladeira et al., 2002; Leite et al., 2006) e boa capacidade de adaptação no Brasil, podem ser importantes na consorciação com capim-elefante (Valentim et al., 2003; Gerdes et al., 2005)

A análise de pastagens consorciadas no decorrer do ano poderia contribuir de forma efetiva para o estudo de sistemas forrageiros com essas espécies, informando as variações qualitativas e contribuindo para melhorar o conhecimento de sua capacidade nutritiva com implicações no manejo dessas forrageiras.

Assim, realizou-se este trabalho com o objetivo de avaliar o valor nutritivo de pastagens de capim-elefante consorciadas com azevém, espécies de crescimento espontâneo e trevo-branco ou amendoim forrageiro submetidas ao manejo com baixa utilização de insumos durante um ano agrícola.

\section{Material e Métodos}

O trabalho foi conduzido no Laboratório de Bovinocultura de Leite da Universidade Federal de Santa Maria, localizado na região fisiográfica denominada Depressão Central do Rio Grande do Sul, com altitude de $95 \mathrm{~m}$, latitude $29^{\circ} 43^{\prime}$ Sul e longitude $53^{\circ} 42^{\prime}$ Oeste, com clima subtropical úmido (Moreno, 1961). Os valores da precipitação anual variam de 1.300 a $1.800 \mathrm{~mm}$ e a temperatura média é de $19,2^{\circ} \mathrm{C}$. O solo é classificado como Argissolo vermelho distrófico arênico (Embrapa, 1999).

A área utilizada, de 1,0 ha, foi dividida em quatro piquetes $(0,25$ ha cada) de capim-elefante (Pennisetum purpureum Schum.), cv. Merckeron pinda, como base do sistema forrageiro. O capim-elefante foi estabelecido em linhas afastadas a cada $4 \mathrm{~m}$, entre os anos de 2002 e 2003. Em dezembro de 2004, nas entrelinhas, foi implantado em metade da área (dois piquetes) o amendoim forrageiro (Arachis pintoi Krap. e Greg.), cv. Amarillo, com densidade de semeadura de $12 \mathrm{~kg} / \mathrm{ha}$. Na outra metade, em junho de 2005, mediante escarificação do solo, foi estabelecido o trevo-branco (Trifolium repens L.), cv. Yi, na proporção de $4 \mathrm{~kg} / \mathrm{ha}$, e o azevém (Lolium multiflorum Lam.), cv. Comum, $40 \mathrm{~kg} / \mathrm{ha}$. Na área estabelecida com amendoim forrageiro, a implantação do azevém foi realizada por sobressemeadura. No período estival, permitiu-se nas entrelinhas o desenvolvimento de espécies de crescimento espontâneo.

$\mathrm{Na}$ adubação foram utilizados $40 \mathrm{~kg} / \mathrm{ha} /$ ano de $\mathrm{P}_{2} \mathrm{O}_{5} \mathrm{e}$ $40 \mathrm{~kg} / \mathrm{ha} /$ ano de $\mathrm{K}_{2} \mathrm{O}$, conforme a análise de solo e as recomendações para as leguminosas perenes usadas (SBCS, 2004). No período avaliado, foram utilizados $50 \mathrm{~kg} / \mathrm{ha} /$ ano de nitrogênio, na forma de ureia, divididos em duas aplicações.

Foram avaliados dois sistemas forrageiros: capimelefante + trevo-branco + azevém + espécies de crescimento espontâneo; e capim-elefante + amendoim forrageiro + azevém + espécies de crescimento espontâneo. Parte da área (25\%) foi ocupada pelo capim-elefante e o restante, pelas espécies presentes na entrelinha. 
A pesquisa foi conduzida no período entre 24/5/2005 e $2 / 5 / 2006$, perfazendo um total de 343 dias; de 24/5/2005 a 25/4/2006 (336 dias), no sistema de consórcio com amendoim forrageiro e de 11/6/2005 a 1/5/2006 (326 dias) no sistema com trevo-branco. No período, foram realizados nove ciclos de pastejo por tratamento, quatro no período hibernal (julho a outubro), correspondendo ao ciclo de produção do azevém, e cinco no estival (dezembro a maio). O tempo de ocupação variou de 1 a 2 dias.

Na avaliação, foram usadas vacas em lactação da raça Holandesa, com $530 \pm 30,5 \mathrm{~kg}$ e produção de $17 \pm 2,3 \mathrm{~kg} / \mathrm{dia}$, recebendo suplementação diária com 3,5 kg de concentrado, com 20\% de proteína bruta (durante todo o ano agrícola), e silagem de milho (apenas no período hibernal), com 3,5 kg de matéria seca (MS), nos pastejos entre os meses de julho e outubro, fornecidos após as ordenhas (manhã e tarde). As vacas foram mantidas nas pastagens das $9 \mathrm{~h}$ às $16 \mathrm{~h}$ e das 18 h às 7 h, com sombra, água e sal mineral à disposição.

Durante o período hibernal, a utilização da pastagem foi determinada com base nas espécies estabelecidas na entrelinha, de modo que o pastejo se iniciou quando as espécies apresentavam aproximadamente $20 \mathrm{~cm}$ de altura. No período estival, o critério para utilização da pastagem foi a altura do capim-elefante, entre 100 e $120 \mathrm{~cm}$.

Procurou-se manter a oferta de forragem entre 8 e $10 \mathrm{~kg}$ de MS/100 kg de peso vivo para a entrelinha e de $4 \mathrm{~kg}$ de MS/100 kg de peso vivo para a biomassa de lâminas foliares de capim-elefante, com base na massa de forragem inicial da pastagem, estimada pela técnica de dupla amostragem (Wilm et al., 1944), com cinco cortes na entrelinha (rente ao solo) e 20 estimativas visuais, repetindo-se o processo na linha (cortes a $50 \mathrm{~cm}$ do solo). As amostras provenientes dos cortes foram pesadas e homogeneizadas, retirando-se uma subamostra para separação botânica e dos componentes estruturais do capim-elefante e do azevém. Esses materiais foram mantidos em estufa de ar forçado a $65^{\circ} \mathrm{C}$ por 72 horas para determinação do teor de matéria seca. Nos cálculos de massa de forragem e carga animal, considerou-se de 25\% a área ocupada pelo capim-elefante (linha) e de 75\% a área de espécies presentes na entrelinha.

Para determinação do valor nutritivo, foram retiradas em cada avaliação (pastejo) amostras de simulação da pastagem (Euclides et al., 1992) e, isoladamente, do capimelefante e da entrelinha no momento da entrada e da saída dos animais. As amostras foram secas, moídas e posteriormente analisadas para determinação dos teores de PB (método de Kjeldahl - AOAC, 1984) e FDN (Van Soest et al., 1991), e da digestibilidade in vitro da MS e MO (Tilley \& Terry, 1963). Os valores da DIVMO foram utilizados para estimar o NDT das pastagens, conforme a seguinte equação: NDT = MO \{[26,8+0,595(DIVMO)]/100\}, descrita por Kunkle \& Bates (1998), na qual NDT são nutrientes digestíveis totais (\%); MO é matéria orgânica (\%) e DIVMO é digestibilidade in vitro da matéria orgânica (\%).

O delineamento experimental foi o de blocos ao acaso (ano de implantação do capim-elefante), com dois sistemas forrageiros, duas repetições de área (piquetes) e parcelas subdivididas no tempo (pastejos). Os dados foram submetidos à análise de variância a 5\% de significância. As variáveis que apresentaram interação tratamento (sistema forrageiro) $\times$ pastejos foram submetidas à análise de regressão polinomial. O modelo estatístico referente à análise das variáveis estudadas da pastagem foi representado por: $\mathrm{Yijk}=\mu+\mathrm{Ti}+\mathrm{Bj}(\mathrm{Ti})+\mathrm{Pk}+\mathrm{TiPk}+\varepsilon_{\mathrm{ijk}}$, em que: Yijk = variáveis dependentes; $\mathrm{i}=$ índice de tratamentos (sistemas forrageiros); $\mathrm{j}$ = índice de repetições; $\mathrm{k}$ = índice de pastejos; $\mu$ = média de todas as observações; $\mathrm{Ti}$ = efeito dos sistemas forrageiros; $\mathrm{Bj}=$ efeito dos blocos/piquetes; $\mathrm{Bj}$ $(\mathrm{Ti})=$ efeito de piquete dentro de tratamento (erro a); $\mathrm{Pk}=$ efeito dos pastejos; TiPk = interação tratamento $\times$ pastejos; e $\varepsilon_{\mathrm{ijk}}=$ erro experimental residual (erro b). As análises foram conduzidas com auxílio do pacote estatístico SAS, versão 6.12(1997).

\section{Resultados e Discussão}

Durante o período experimental, foram realizados nove ciclos de pastejo em ambos os sistemas forrageiros: quatro no período hibernal e cinco no estival. O tempo médio de ocupação, independentemente da época do ano, variou de 1 a 2 dias e o tempo médio de descanso foi de 35 e 38 dias, respectivamente, nos períodos hibernal e estival. Períodos curtos de ocupação e de descanso (próximo a 30 dias para espécies tropicais) estão associados a melhor qualidade da forragem ofertada (Deresz et al., 2001; Soares et al., 2004).

Os ciclos de pastejo adotados estão dentro das recomendações de Hillesheim (1995) de que é possível obter valores de digestibilidade verdadeira superiores a $65 \%$ mantendo-se períodos de crescimento de aproximadamente 42 dias. De acordo com Deresz et al. (2001), vacas submetidas ao pastejo de capim-elefante com 30 dias de descanso produzem mais leite que aquelas em período de descanso de 45 dias.

Nos sistemas constituídos, o capim-elefante apresentou a maior contribuição de massa de forragem (Tabela 1 ), que foi maior no período estival, época de maior crescimento do capim-elefante. A biomassa de lâminas foliares do capim-elefante teve mesmo comportamento, com maior contribuição nos meses de janeiro e fevereiro, com 1,17 e 
1,54 t/ha no sistema forrageiro com trevo-branco e 1,38 e $1,38 \mathrm{t} / \mathrm{ha}$ no sistema com amendoim forrageiro, respectivamente. No período hibernal, os menores valores foram verificados no mês de setembro, de 0,40 e 0,39 t/ha para os sistemas com trevo-branco e amendoim forrageiro, respectivamente. Esses valores, apesar de inferiores aos obtidos no período estival, comprovam que o capimelefante continuou produzindo mesmo nas épocas mais frias do ano. Ressalta-se que, no período em análise, a temperatura média foi de $16,6^{\circ} \mathrm{C}$, superior à média climática, de $15,3^{\circ} \mathrm{C}$.

A massa de forragem do azevém foi similar $(\mathrm{P}>0,05)$ entre os sistemas forrageiros avaliados, com pico de produção na avaliação feita em setembro. A massa de forragem média do azevém, mesmo ocupando $75 \%$ da área, foi inferior à observada por Difante et al. (2006), que verificaram em média 1,58 t/ha de MS com pastagem exclusiva dessa forrageira, adubada com $100 \mathrm{~kg} /$ ha de nitrogênio, com oferta de forragem média de 8,8 kg de MS/100 kg de peso vivo.

As leguminosas, como esperado, apresentaram ciclos produtivos distintos e, no período estival, tiveram massa de forragem similar $(\mathrm{P}>0,05)$. No período hibernal, o trevobranco foi superior $(\mathrm{P}<0,05)$ ao amendoim forrageiro, em razão de sua alta produção, normalmente observada na estação primaveril. Os valores obtidos são inferiores aos verificados por Scheffer-Basso et al. (2005), no Rio Grande do Sul. Esses autores trabalharam com estratégias distintas de manejo e com diferentes espécies de leguminosas estabelecidas na forma exclusiva e obtiveram produção média de forragem de 1,04 t/ha/ano, em nove cortes, com maiores produções nos cortes realizados entre outubro e dezembro.

A massa de forragem das espécies de crescimento espontâneo nas entrelinhas foi constituída basicamente pelo Paspalum conjugatum, principalmente no período estival. Entre as outras espécies, destacam-se papuã (Urochloa plantaginea), milhã (Digitaria sanguinalis), guanxuma (Sida spp) e erva-de-bicho(Polygonum persicaria).

A participação de material morto, especialmente na entrelinha, foi maior no período estival, em razão da presença de material senescente de final de ciclo do azevém e das espécies de crescimento espontâneo.

A carga animal média anual correspondeu a 2,03 e 2,09UA/ha para os sistemas com trevo-branco e amendoim forrageiro, respectivamente, e não diferiu $(\mathrm{P}>0,05)$ entre esses sistemas nem entre os pastejos.

O teor médio de FDN da pastagem total foi mais baixo $(\mathrm{P}<0,05)$ no sistema forrageiro com trevo-branco (Tabela 2 ), em virtude da presença dessa forrageira no início do período estival, que, nesta época, apresenta seu ápice de produção. Os valores de FDN da entrelinha apresentaram mesmo comportamento, com diferença significativa $(\mathrm{P}<0,05)$ na média e em três pastejos (outubro, dezembro e janeiro), o que coincidiu com o período de maior participação do trevo-branco no pasto. Essa assertiva pode ser justificada pela correlação negativa entre a porcentagem de FDN total e a massa de forragem do trevo-branco $(-0,6179 ; \mathrm{P}=0,0063)$. No sistema com amendoim forrageiro, a correlação entre massa de forragem do amendoim forrageiro e a FDN da pastagem foi direta $(0,5058 ; \mathrm{P}=0,0322)$ e indica que essa forrageira possui menor qualidade em relação ao trevobranco. Em ambos os sistemas, foram encontradas correlações inversas, normalmente esperadas, da porcentagem de FDN com a DIVMS, DIVMO e o teor de NDT e diretas com a massa de forragem, as espécies de crescimento espontâneo e a carga animal.

Os valores de FDN total da pastagem, de 50\% aproximadamente, foram similares aos obtidos por Balocchi et al.

Tabela 1 - Valores médios de massa de forragem total e dos componentes botânicos e estruturais do pasto, em t/ha de matéria seca, e carga animal (unidade animal/ha) nos sistemas forrageiros em cada período

\begin{tabular}{|c|c|c|c|c|}
\hline \multirow[b]{2}{*}{ Variável } & \multicolumn{2}{|c|}{ Hibernal ${ }^{1}$} & \multicolumn{2}{|c|}{ Estival $^{2}$} \\
\hline & $\begin{array}{l}\text { Consórcio com } \\
\text { trevo-branco }\end{array}$ & $\begin{array}{l}\text { Consórcio com } \\
\text { amendoim forrageiro }\end{array}$ & $\begin{array}{l}\text { Consórcio com } \\
\text { trevo-branco }\end{array}$ & $\begin{array}{l}\text { Consórcio com } \\
\text { amendoim forrageiro }\end{array}$ \\
\hline Massa de forragem total & $3,06 b$ & $3,79 a$ & $4,32 b$ & $5,24 a$ \\
\hline Capim-elefante & $2,06 b$ & $2,96 a$ & $2,97 b$ & $3,85 a$ \\
\hline Lâmina foliar do capim-elefante & 0,58 & 0,64 & 1,07 & 1,26 \\
\hline Material morto do capim-elefante & $0,29 b$ & $0,47 \mathrm{a}$ & 0,33 & 0,44 \\
\hline Azevém & 0,58 & 0,59 & - & - \\
\hline Leguminosas & $0,20 \mathrm{a}$ & $0,04 b$ & 0,31 & 0,31 \\
\hline Espécies de crescimento espontâneo & 0,09 & 0,11 & 0,22 & 0,33 \\
\hline Paspalum conjugatum & 0,01 & 0,06 & 0,62 & 0,44 \\
\hline Material morto da entrelinha & 0,07 & 0,06 & 0,20 & 0,30 \\
\hline Carga animal & 2,22 & 2,29 & 3,14 & 3,01 \\
\hline
\end{tabular}

${ }^{1}$ maio a setembro de 2005 (quatro ciclos de pastejo); ${ }^{2}$ outubro a abril 2005 - 2006 (cinco ciclos de pastejo)

'a b' médias seguidas por letras distintas na linha em cada período diferem $(\mathrm{P}<0,05)$ entre si pelo teste $\mathrm{F}$. 
(2002), de 49,16\%, em pastagens constituídas basicamente de azevém.

A análise de regressão do teor de FDN total e da entrelinha mostrou que o modelo matemático que mais se ajustou foi o cúbico, com início descendente, em ambos os sistemas (Figura 1). A correlação dessa variável com o número de pastejos indica que os valores aumentam no período estival $(0,5123 ; \mathrm{P}=0,0014$ e 0,$5624 ; \mathrm{P}=0,0004$, respectivamente, para os sistemas com trevo-branco e amendoim forrageiro), em decorrência da maior participação do capim-elefante e de outras espécies tropicais, cujos teores de FDN normalmente são superiores aos das espécies de ciclo hibernal.

Os valores de FDN do capim-elefante não diferiram entre os sistemas forrageiros e a média foi de $55,17 \%$ de FDN. Deresz et al. (2006), trabalhando com capim-elefante, cv. Napier, adubado com 200 kg/ha/ano de nitrogênio e manejado sob sistema de pastejo rotacionado, com 30 dias de descanso e três de ocupação, utilizaram vacas mestiças Holandês × Zebu em lactação e observaram em amostras de

Tabela 2 - Valor nutritivo de sistemas forrageiros com consórcio de espécies leguminosas

\begin{tabular}{|c|c|c|c|c|c|c|c|c|c|c|c|}
\hline Variável (\%) & SF & $\begin{array}{l}10(\mathrm{Jul} / \\
2005)\end{array}$ & $\begin{array}{c}20 \text { (Ago/ } \\
(2005)\end{array}$ & $\begin{array}{c}\text { 30 (Ago/ } \\
2005)\end{array}$ & $\begin{array}{l}40 \text { (Out/ } \\
2005)\end{array}$ & $\begin{array}{c}\text { 50 (Dez/ } \\
2005)\end{array}$ & $\begin{array}{l}6 \underline{0}(\mathrm{Jan} / \\
(2006)\end{array}$ & $\begin{array}{c}70 \text { (Fev/ } \\
2006)\end{array}$ & $\begin{array}{c}\text { 80 (Mar/ } \\
2006)\end{array}$ & $\begin{array}{c}90 \text { (Abr/ } \\
2006)\end{array}$ & Média \\
\hline \multirow[t]{2}{*}{ FDN TOT } & 1 & 50,31 & 42,64 & 37,14 & 44,25 & $35,76 b$ & 55,41 & 52,35 & 59,03 & 52,45 & $47,71 b \pm 1,14$ \\
\hline & 2 & 51,22 & 45,05 & 44,20 & 52,53 & $54,12 \mathrm{a}$ & 56,78 & 51,87 & 58,13 & 52,67 & $51,84 a \pm 1,14$ \\
\hline \multirow[t]{2}{*}{ FDN EL } & 1 & 35,08 & 33,34 & 34,13 & $37,65 b$ & $23,05 b$ & $41,83 b$ & 54,96 & 59,14 & 47,75 & $40,77 b \pm 0,71$ \\
\hline & 2 & 44,77 & 44,56 & 35,00 & $54,75 a$ & $50,22 a$ & $51,52 \mathrm{a}$ & 53,04 & 59,15 & 47,38 & $48,90 a \pm 0,71$ \\
\hline CV (\%) & & 8,13 & 4,59 & 2,27 & 3,83 & 3,20 & 4,47 & 5,02 & 2,03 & 2,30 & 6,25 \\
\hline CV (\%) & & 2,04 & 2,25 & 1,89 & 2,47 & 2,56 & 5,30 & 4,16 & 3,90 & 5,17 & 3,52 \\
\hline \multirow[t]{2}{*}{ РВ ТОТ } & 1 & 19,39 & 19,06 & 19,64 & 18,46 & 16,52 & $14,52 \mathrm{a}$ & 10,20 & 10,72 & 12,66 & $15,69 a \pm 1,46$ \\
\hline & 2 & 17,84 & 18,45 & 19,29 & 15,53 & 12,90 & $10,70 \mathrm{~b}$ & 11,84 & 11,44 & 13,59 & $14,62 b \pm 1,46$ \\
\hline CV (\%) & & 11,79 & 5,53 & 3,44 & 6,55 & 8,87 & 3,21 & 6,89 & 11,74 & 13,40 & 8,40 \\
\hline \multirow[t]{2}{*}{ PB EL } & 1 & 23,30 & 21,42 & 18,67 & 20,26 & $20,17 \mathrm{a}$ & 12,88 & 8,13 & 8,99 & 9,57 & $15,93 a \pm 0,32$ \\
\hline & 2 & 21,58 & 20,06 & 20,51 & 14,63 & $11,63 b$ & 9,08 & 11,27 & 9,48 & 10,96 & $14,36 b \pm 0,32$ \\
\hline \multirow[t]{2}{*}{ DIVMSTOT } & 1 & 76,89 & 91,74 & 82,82 & 80,74 & $78,71 \mathrm{a}$ & 67,01 & 72,51 & 71,05 & 74,02 & $77,28 a \pm 0,63$ \\
\hline & 2 & 70,70 & 89,14 & 77,67 & 76,26 & $68,64 b$ & 67,78 & 72,89 & 68,50 & 71,48 & $73,72 b \pm 0,63$ \\
\hline CV (\%) & & 2,59 & 2,16 & 2,31 & 2,05 & 2,09 & 2,56 & 1,94 & 5,13 & 8,07 & 3,77 \\
\hline \multirow[t]{2}{*}{ DIVMS EL } & 1 & $91,26 a$ & 94,99 & 86,12 & $83,61 \mathrm{a}$ & $89,63 a$ & 77,27 & 68,91 & 69,68 & 69,34 & $81,20 a \pm 0,51$ \\
\hline & 2 & $79,17 b$ & 93,42 & 87,65 & $73,08 b$ & $68,95 b$ & 68,46 & 72,68 & 66,01 & 72,56 & $75,78 b \pm 0,51$ \\
\hline CV (\%) & & 2,74 & 2,29 & 0,93 & 0,33 & 1,32 & 3,15 & 8,12 & 5,01 & 2,45 & 3,58 \\
\hline \multirow[t]{2}{*}{ DIVMS CE } & 1 & 66,48 & 75,82 & 69,22 & 70,79 & 64,83 & 65,33 & 67,54 & 66,31 & 63,36 & $67,74 b \pm 0,77$ \\
\hline & 2 & 72,04 & 77,52 & 72,46 & 72,91 & 66,65 & 63,48 & 71,56 & 68,40 & 72,40 & $70,82 \mathrm{a} \pm 0,77$ \\
\hline CV (\%) & & 3,93 & 2,06 & 2,11 & 5,26 & 2,21 & 5,87 & 4,69 & 7,51 & 4,30 & 4,75 \\
\hline \multirow[t]{2}{*}{ DIVMOTOT } & 1 & $76,06 \mathrm{a}$ & 91,91 & 81,70 & 78,71 & 77,91 & 64,89 & 70,48 & 69,33 & 72,24 & $75,92 a \pm 0,70$ \\
\hline & 2 & $68,24 b$ & 89,15 & 76,29 & 74,52 & 68,60 & 65,87 & 71,74 & 66,57 & 69,45 & $72,27 b \pm 0,70$ \\
\hline CV (\%) & & 2,48 & 2,10 & 1,85 & 1,68 & 3,33 & 1,84 & 2,76 & 5,48 & 8,51 & 3,97 \\
\hline \multirow[t]{2}{*}{ NDT EL } & 1 & 69,01 & 74,00 & 71,01 & 68,39 & $74,81 \mathrm{a}$ & 66,11 & 63,66 & 61,03 & 60,04 & $67,56 a \pm 0,36$ \\
\hline & 2 & 63,92 & 73,82 & 71,70 & 63,95 & $60,64 b$ & 61,65 & 64,35 & 58,62 & 62,24 & $64,55 b \pm 0,36$ \\
\hline CV (\%) & & 1,75 & 2,36 & 1,86 & 3,45 & 0,66 & 1,95 & 6,90 & 5,21 & 1,34 & 3,48 \\
\hline \multirow[t]{2}{*}{ NDT CE } & 1 & 56,93 & 62,56 & 59,86 & 59,22 & 59,56 & 58,30 & 60,36 & 58,27 & 55,96 & $59,00 \pm 0,72$ \\
\hline & 2 & 59,88 & 63,27 & 61,60 & 61,54 & 60,43 & 57,24 & 63,03 & 60,01 & 58,04 & $60,56 \pm 0,72$ \\
\hline CV (\%) & & 1,74 & 1,37 & 3,60 & 5,50 & 3,61 & 4,39 & 4,06 & 6,67 & 2,04 & 4,23 \\
\hline
\end{tabular}

'a b' médias seguidas por letras distintas na coluna diferem $(\mathrm{P}<0,05)$ entre si pelo teste $\mathrm{F}$.

FDN - fibra em detergente neutro; PB - proteína bruta; DIVMS - digestibilidade in vitro da matéria seca; DIVMO - digestibilidade in vitro da matéria orgânica; NDT - nutrientes digestíveis totais; TOT - total da pastagem; EL - entrelinha; CE - capim-elefante; CV - coeficiente de variação; SF - sistema forrageiro. 
A

$\mathrm{SF} 1=\mathrm{CE}+\mathrm{AZ}+\mathrm{TB}+\mathrm{ECE}$

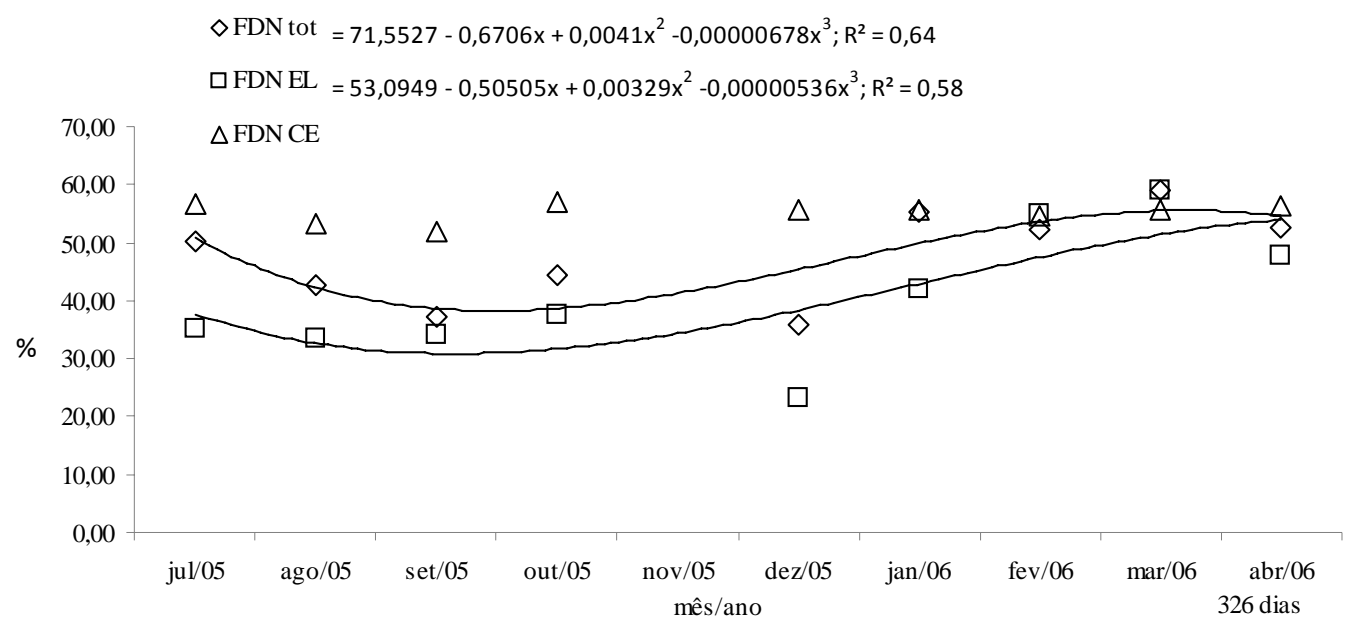

B

$\mathrm{SF} 2=\mathrm{CE}+\mathrm{AZ}+\mathrm{AF}+\mathrm{ECE}$

$\diamond$ FDN tot $=71,5527-0,6706 x+0,0041 x^{2}-0,00000678 x^{3} ; R^{2}=0,64$

$\square$ FDN EL $=51,0663-0,24935 \mathrm{x}+0,00207 \mathrm{x}^{2}-0,000004 \mathrm{x}^{3} ; \mathrm{R}^{2}=0,49$

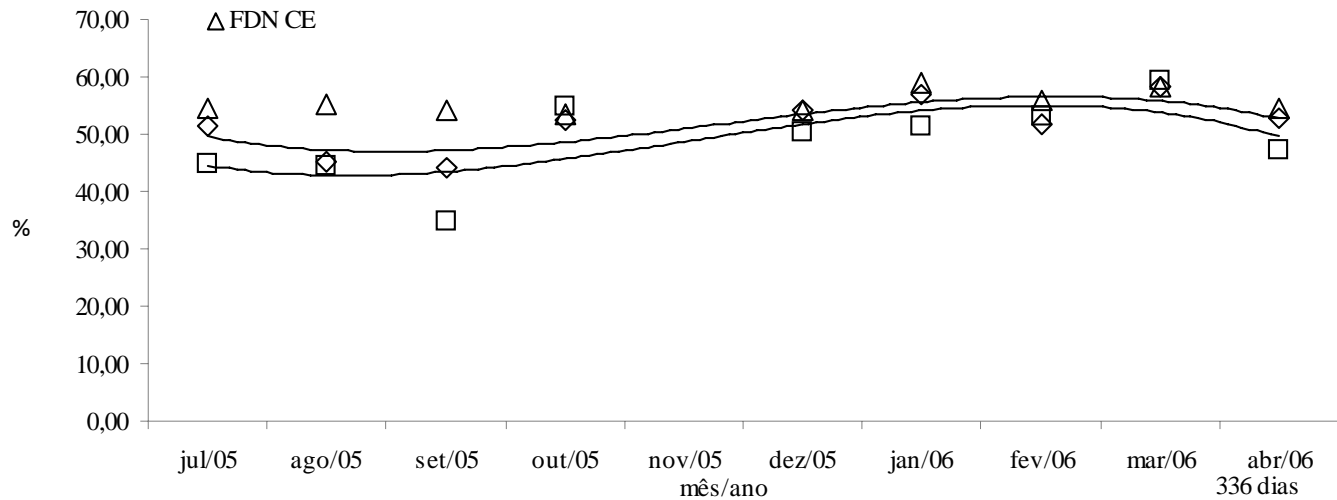

CE - capim-elefante; AZ - azevém; TB - trevo-branco; AF - amendoim forrageiro; ECE - espécies de crescimento espontâneo.

Figura 1 - Fibra em detergente neutro da pastagem total (FDNtot) da entrelinha (FDNel) e do capim-elefante (FDNce) nos sistemas forrageiros com trevo-branco (Figura A) e amendoim forrageiro (Figura B).

pastejo simulado teor médio de 69,14\% de FDN. Deresz et al. (2001), na estação das águas e utilizando $200 \mathrm{~kg} / \mathrm{ha}$ de nitrogênio, observaram valores de FDN entre 66,5 e 67,2\% em períodos de descanso de 30 e 45 dias, respectivamente. Lima et al. (2004) obtiveram teores de 76,3 e 75,1\% para as folhas de capim-elefante, cv. Guaçu, no pré e pós-pastejo, com períodos de descanso de 40 dias e adubação nitrogenada de $250 \mathrm{~kg} / \mathrm{ha} / \mathrm{ano}$. Gerdes et al. (2005), estudando misturas forrageiras, encontraram teores médios de 69,5\% de FDN em seis pastejos para a mistura de capim-aruana com aveia-preta e azevém utilizando $200 \mathrm{~kg} / \mathrm{ha}$ /ano de nitrogênio. Avaliando apenas feno de amendoim forrageiro, Ladeira et al. (2002) encontraram valores de 52,5\%.
Os teores de PB (Tabela 2) tiveram comportamento similar ao da FDN, com melhores valores na pastagem total e na entrelinha no sistema forrageiro com trevo-branco. No capim-elefante, os teores de PB foram semelhantes $(\mathrm{P}>0,05)$ entre os sistemas forrageiros. Os resultados da análise de regressão (Figura 2) indicam efeito significativo $(P<0,05)$ e melhor qualidade proteica do capim-elefante no período hibernal. Esse comportamento deve-se, especialmente, à consorciação com o azevém, que normalmente apresenta teores mais altos de $\mathrm{PB}$ em relação às gramíneas perenes de ciclo estival (Stobbs, 1973). Outra contribuição para essa melhor qualidade proteica deve-se ao capim-elefante, que apresentou melhor teor de PB no período hibernal. Esse 
$\mathrm{SF} 1=\mathrm{CE}+\mathrm{AZ}+\mathrm{TB}+\mathrm{ECE}$

A

$\diamond \mathrm{PB}$ tot $=14,56026+0,15094 \mathrm{x}-0,00119 \mathrm{x}^{2}+0,00000215 \mathrm{x}^{3} ; \mathrm{R}^{2}=0,89$

$\square$ PBEL $=19,6740+0,9817 x-0,00959 x^{2}+0,00000171 x^{3} ; R^{2}=0,83$

$\triangle \mathrm{PBCE}=17,7044-0,0292 \mathrm{x}+0,00000382 \mathrm{x}^{2} ; \mathrm{R}^{2}=0,72$

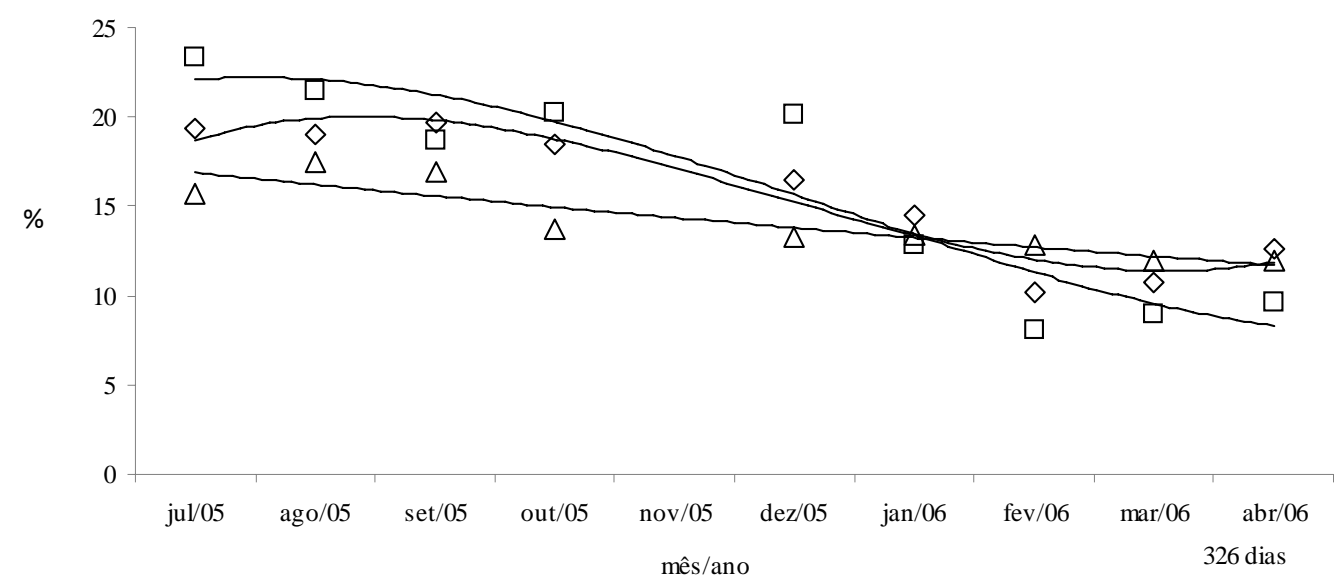

B

$\mathrm{SF} 2=\mathrm{CE}+\mathrm{AZ}+\mathrm{AF}+\mathrm{ECF}$

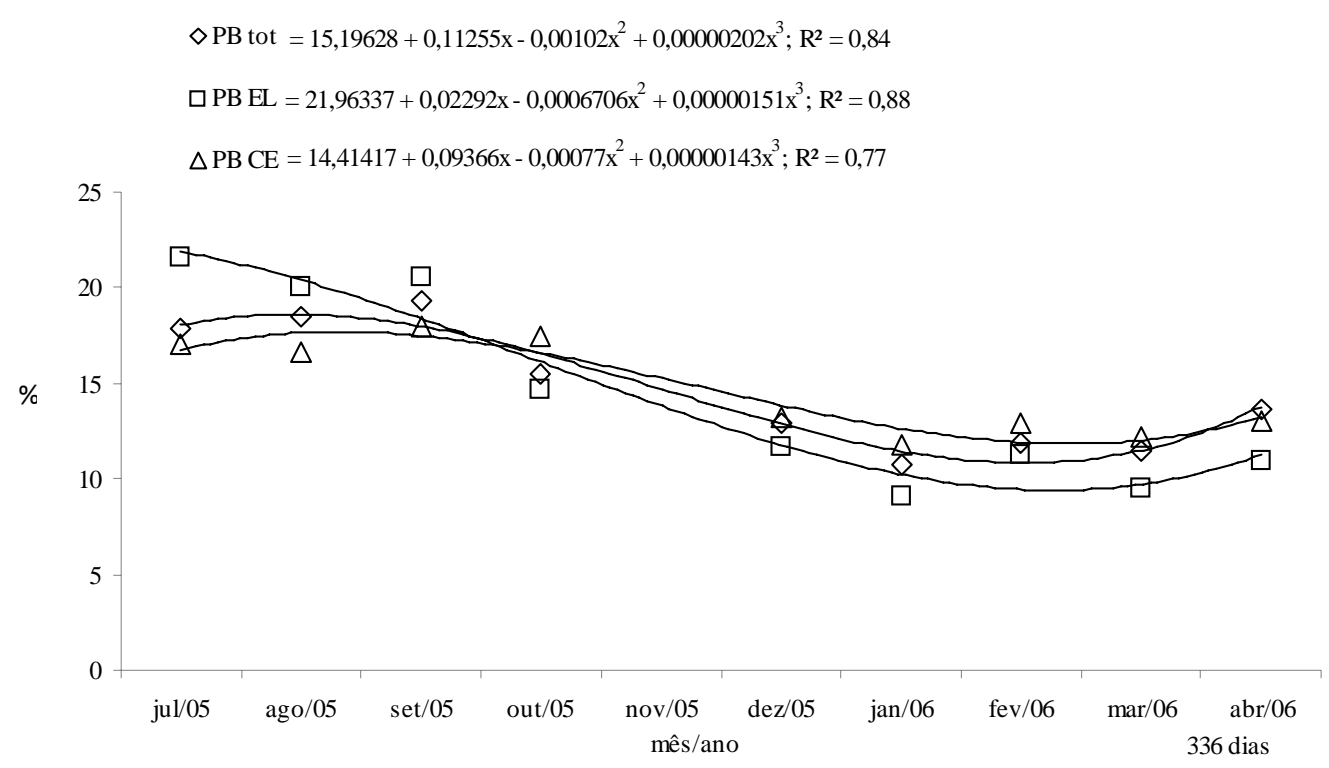

CE - capim-elefante; AZ - azevém; TB - trevo-branco; AF - amendoim forrageiro; ECE - espécies de crescimento espontâneo.

Figura 2 - Proteína bruta da pastagem total (PBtot), da entrelinha (PBel) e do capim- elefante (PBce) nos sistemas forrageiros SF1 (Figura A) e SF2 (Figura B).

comportamento justifica-se pelo menor crescimento dessa forrageira nesse período. Segundo Poli (1992), durante o desenvolvimento, as plantas elevam seus teores de MS, parede celular, celulose, fibra e lignina e diminuem os de PB e DIVMS, comportamento que se acentua no verão, quando o crescimento das plantas tropicais é mais intenso. Townsend et al. (1994), trabalhando com o mesmo cultivar de capimelefante, verificaram em uma sequência de três ciclos de pastejo, de novembro a março, 8,9; 11,0 e 10,9\% de PB, também por simulação de pastejo, o que confirma essa tendência de melhor qualidade na porção comestível em períodos de menor crescimento dessa forrageira. Valor similar às médias encontradas neste trabalho foi reportado por Deresz et al. (2006), que verificaram teor médio de 13,58\% de PB em pastagem exclusiva de capim-elefante adubado com $200 \mathrm{~kg} / \mathrm{ha} / \mathrm{ano}$.

No sistema forrageiro com trevo-branco (Tabela 2), os valores mais elevados da contribuição proteica das leguminosas estão associados à maior contribuição de massa de forragem do trevo-branco no período estival. 
Teor mais alto, de 24,41\% de PB, foi obtido por Leite et al. (2006), em pastagem exclusiva de trevo-branco em sistema rotacionado com suínos.

No sistema com amendoim forrageiro, o comportamento do teor de PB foi mais uniforme no decorrer do período experimental (Figura 2 B). O valor médio inferior $(\mathrm{P}<0,05) \mathrm{em}$ relação ao sistema com trevo-branco deve-se, possivelmente, ao menor consumo daquela forrageira. Outra justificativa para essa menor variação proteica no decorrer do ano agrícola no sistema com amendoim forrageiro deve-se à coincidência do período de maior produção de massa de forragem do amendoim forrageiro com a do capim-elefante. Como o teor de PB da leguminosa é mais elevado, variando de 13 a 25\% (Lascano, 1994), compensa o declínio no capimelefante no período estival (Tabela 2).

Em ambos os sistemas forrageiros, foram encontradas correlações negativas entre o teor de PB e a massa de forragem do capim-elefante, espécies tropicais de crescimento espontâneo e Paspalum conjugatum, o que confirmaa menor qualidade dessas forrageiras em relação às de produção hibernal (Stobbs, 1973).

Para as digestibilidades in vitro da MS e MO, os dados na pastagem total e da entrelinha foram melhores $(\mathrm{P}<0,05)$ no sistema forrageiro com trevo-branco, acompanhando os resultados verificados para o teor de PB (Tabela 2). Resultados da análise de regressão comprovam

A

$$
\mathrm{SF} 1=\mathrm{CE}+\mathrm{AZ}+\mathrm{TB}+\mathrm{ECE}
$$

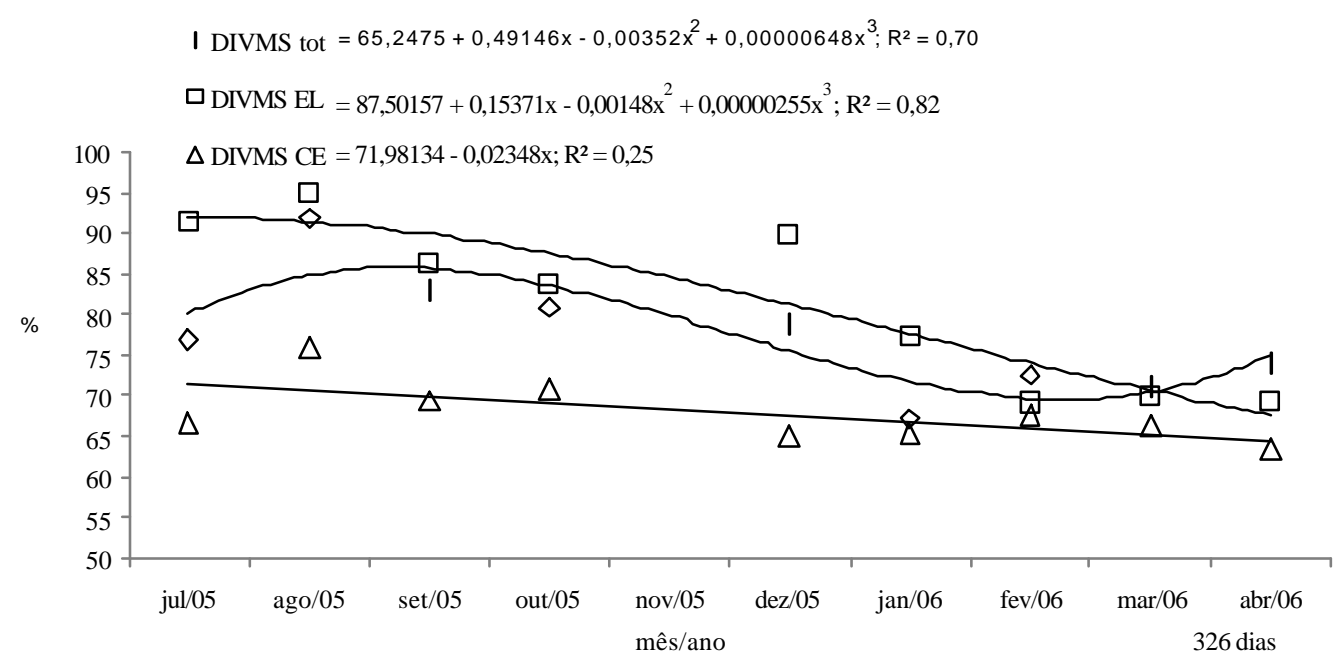

B

$\mathrm{SF} 2=\mathrm{CE}+\mathrm{AZ}+\mathrm{AF}+\mathrm{ECE}$

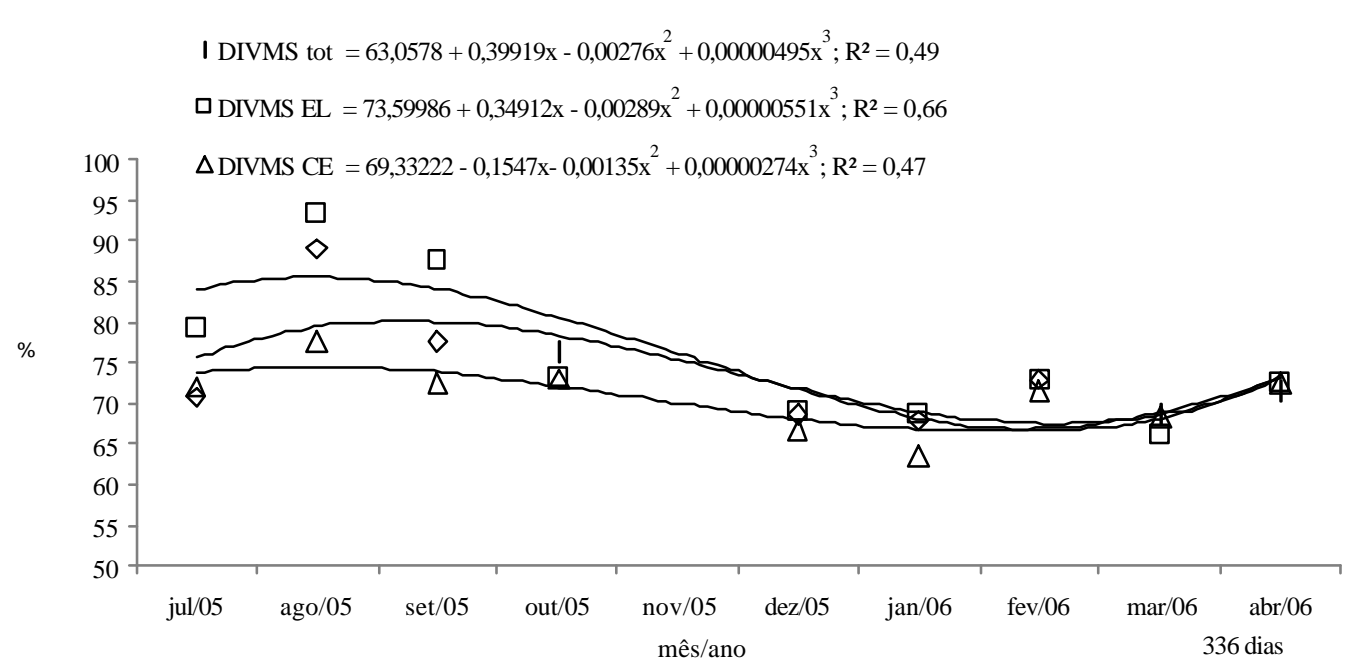

CE - capim-elefante; AZ - azevém; TB - trevo-branco; AF - amendoim forrageiro; ECE - espécies de crescimento espontâneo.

Figura 3 - Digestibilidade in vitro da matéria seca da pastagem total (DIVMStot), da entrelinha (DIVMSel) e do capim-elefante (DIVMSce)nos sistemas forrageiros com trevo-branco (Figura A) e com amendoim forrageiro (Figura B). 
comportamento similar em ambos os sistemas forrageiros para essas variáveis, com efeito inicial ascendente, o que indica melhor qualidade no período hibernal (Figura 3). Esse comportamento deve-se à presença do azevém, à melhor digestibilidade do capim-elefante nesse período e à crescente participação das leguminosas. Resultados das correlações entre DIVMS e biomassa de lâminas foliares do capim-elefante $(-0,7296 ; \mathrm{P}=0,0006$, no SF1 e -0,6805; $\mathrm{P}=0,0019$, no sistema com amendoim forrageiro) indicam que a espécie predominante da pastagem apresenta menor digestibilidade em seu período de maior crescimento.

A digestibilidade do capim-elefante, em média (Tabela 2), foi melhor $(\mathrm{P}<0,05)$ no sistema forrageiro com amendoim forrageiro. No sistema com trevo-branco, a DIVMS teve comportamento linear descendente, enquanto, no sistema com amendoim forrageiro, o efeito foi cúbico, com início ascendente. Esses resultados apontam possível contribuição (indireta) do amendoim forrageiro na elevação da digestibilidade do capim-elefante.

Os valores médios obtidos para a DIVMS do capimelefante são mais elevados que os observados por Deresz et al. (2006), que, usando o mesmo tipo de amostragem, encontraram valor de 63,77\% em pastagem de capim-elefante utilizando 200 kg/ha/ano de nitrogênio.

Considerando a DIVMS da pastagem total, o valor próximo a $74 \%$ se assemelha às médias encontradas por Paim \& Riboldi (1994), de 63,39 a 73,83\%, em pastagens de trevo-branco, azevém e pensacola, no primeiro e no segundo ano de avaliação, respectivamente. Para a massa de forragem média presente na entrelinha, tanto a DIVMS quanto a DIVMO foram mais elevadas $(\mathrm{P}<0,05)$ no sistema forrageiro com trevo-branco, principalmente em decorrência da maior contribuição dessa espécie na dieta dos animais, em relação ao amendoim forrageiro.

Os teores de NDT obtidos indicam estreita associação com aqueles obtidos para a DIVMS e a DIVMO (Tabela 2). Os valores médios encontrados, próximos a 64\% de NDT, são superiores aos obtidos por Flemming et al. (2004), que verificaram média de $61 \%$ de NDT em pastagens de azevém em estádio vegetativo. Teor de NDT de 66,4\%, similar ao deste trabalho, foi obtido por Ladeira et al. (2002), com feno de amendoim forrageiro.

Em análise conjunta das variáveis de valor nutritivo, observou-se que os dados qualitativos da forragem foram em média superiores aos das demais pesquisas citadas, e que a adubação utilizada foi menor. Dessa forma, os resultados apontam para um sinergismo entre as espécies de gramíneas e leguminosas em cada sistema forrageiro, o qual proporciona baixa variação da qualidade entre os pastejos e indica índices elevados para as espécies envolvidas no manejo proposto.

\section{Conclusões}

Os sistemas forrageiros constituídos de capimelefante, azevém, espécies de crescimento espontâneo e trevo-branco ou amendoim forrageiro são viáveis qualitativamente. O sistema forrageiro com trevo-branco apresenta forragem de melhor qualidade, principalmente no período hibernal. O capim-elefante, em consorciação com leguminosas e outras espécies forrageiras de ciclo estival e hibernal, pode ser utilizado no decorrer do ano agrícola em região climática similar à deste trabalho, pois têm bom potencial de produção de massa de forragem e valor nutritivo. A presença de espécies de ciclos e características forrageiras distintas indica possível sinergismo entre essas forrageiras, comprovado pela baixa oscilação das variáveis qualitativas e de produção animal durante o ano agrícola.

\section{Literatura Citada}

ASSMANN, A.L.; PELISSARI, A.; MORAES, A. et al. Produção de gado de corte e acúmulo de matéria seca em sistema de integração lavoura-pecuária em presença e ausência de trevo-branco e nitrogênio. Revista Brasileira de Zootecnia, v.33, n.1, p.37-44, 2004

ASSOCIATION OF OFFICIAL ANALYTICAL CHEMISTS AOAC. Official methods of analysis. 14.ed. Washington, D.C.: 1984. 1094p.

BALOCCHI, O.; PULIDO, R.; FERNÁNDEZ, J. Comportamiento de vacas lecheras en pastoreo com y sin suplementación com concentrado. Agricultura Técnica, v.62, n.1, p.87-98, 2002.

BLASER, R. Forage animal management systems. Blacksburg: Virginia Agricultural Experiment Station and Polytechnic Institute, 1982. p.7 (Bulletin, 86).

DALL'AGNOL, M.; SCHEFFER-BASSO, S.M.; NASCIMENTO, J.A.L. et al. Produção de forragem de capim-elefante sob clima frio. Curva de crescimento e valor nutritivo. Revista Brasileira de Zootecnia, v.33, n.5, p.1110-1117, 2004.

DERESZ, F.; LOPES, F.C.F.; AROEIRA, L.J.M. Produção de leite de vacas mestiças Holandês x Zebu em pastagem de capimelefante, com e sem suplementação durante a época das chuvas. Arquivo Brasileiro de Medicina Veterinária e Zootecnia, v.55, n.3, p.334-340, 2001.

DERESZ, F.; PAIM-COSTA, M.L.; CÓSER, A.C. et al. Composição química, digestibilidade e disponibilidade de capim-elefante cv. Napier manejado sob pastejo rotativo. Revista Brasileira de Zootecnia, v.35, n.3, p.863-869, 2006.

DIFANTE, G.S.; MARCHEZAN, E.; VILLA, S.C.C. et al. Produção de novilhos de corte com suplementação em pastagem de azevém submetida a doses de nitrogênio. Revista Brasileira de Zootecnia, v.35, n.3, p.1107-1113, 2006 (supl.).

EMPRESA BRASILEIRA DE PESQUISA AGROPECUÁRIA EMBRAPA. Centro Nacional de Pesquisa de Solos. Sistema brasileiro de classificação de solos. Brasília: 1999. 412p.

EUCLIDES, V.P.B.; MACEDO, M.C.M.; OLIVEIRA, M.P. Avaliação de diferentes métodos de amostragem (para se estimar o valor nutritivo de forragens) sob pastejo. Revista Brasileira de Zootecnia, v.21, n.4, p.691-702, 1992.

FLEMMING, J.S.; BRUM, J.V.F.; MAIORKA, A. et al. Composição da forragem e os parâmetros de gordura do creme de leite e da manteiga. Archives of Veterinary Science, v.9, n.2, p.31-34, 2004. 
GERDES, L.; MATTOS, H.B.; WERNER, J.C. et al. Composição Química e Digestibilidade da Massa de Forragem em Pastagem Irrigada de Capim-Aruana Exclusivo ou Sobre-Semeado com Mistura de Aveia Preta e Azevém, Revista Brasileira de Zootecnia, v.34, n.4, p.1098-1108, 2005.

HILLESHEIM, A. Manejo do gênero Pennisetum sob pastejo. In: PEIXOTO, A.M.; MOURA, J.C.; FARIA, V.P. (Eds.). Plantas forrageiras de pastagens. Piracicaba: Fundação de Estudos Agrários Luiz de Queiroz, 1995. p.37-56.

HODGSON, J. Grazing management: science into pratice. Essex: Longman Scientific and Tecnichal, 1990. 203p.

KUNKLE, W.E.; BATES, D.B. Evaluating feed purchasing options: energy, protein, and mineral supplements. In: FLORIDA BEEF CATTLE SHORT COURSE, 1998, Gainesville. Proceedings... Gainesville: University of Florida, 1998. p.59-70.

LADEIRA, M.M.; RODRIGUEZ, N.M.; BORGES, I. et al. Avaliação do feno de Arachis pintoi utilizando o ensaio de digestibilidade in vivo. Revista Brasileira de Zootecnia, v.31, n.6, p.2350-2356, 2002.

LASCANO, C.E. Nutritive value and animal production of forage Arachis. In: KERRIDGE, P.C.; HARDY. B. (Eds.). Biology and Agronomy of forage Arachis. Cali: CIAT, 1994. p.109-121.

LEITE, D.M.G.; SILVA, M.A.; MEDEIROS, R.B. et al. Efeito de diferentes sistemas de pastejo sobre o desempenho de suínos mantidos em pastagem de trevo-branco (Trifolium repens L.), Revista Brasileira de Zootecnia, v.35, n.3, p.792-796, 2006.

LIMA, M.L.P.; BERCHIELLI, T.T.; LEME, P.R. et al. Concentração de nitrogênio uréico plasmático (nup) e produção de leite de vacas mestiças mantidas em gramíneas tropicais sob pastejo rotacionado. Revista Brasileira de Zootecnia, v.33, n.6, p.1616-1626, 2004.

MOREnO, J.A. Clima do Rio Grande do Sul. Porto Alegre: Secretaria da Agricultura, 1961. 41p.

OLIVO, C.J.; SOBCZAK, M.F.; CHARÃO, P.S. et al. [2006]. Avaliação de uma pastagem de capim-elefante, manejada sob princípios agroecológicos, no período estival. Livestock Research for Rural Development, v.18, n.2, 2006. Disponível em: <http://www.cipav.org.co/lrrd/lrrd18/2/oliv18021.htm>. Acesso em: 10/2/2006.

PAIM, N.R.; RIBOLDI, J. Duas novas cultivares de trevo-branco comparadas com outras disponíveis no Rio Grande do Sul, em associação com gramíneas. Pesquisa Agropecuária Brasileira, v.29, n.1, p.43-53, 1994.

POLI, C.H.E.C. Desenvolvimento morfológico, produção de forragem, proteína bruta e digestibilidade in vitro de cinco cultivares de capim-elefante (Pennisetum purpureum, Schum.). 1992. 148f. Dissertação (Mestrado em Zootecnia) Faculdade de Agronomia, Universidade Federal do Rio Grande do Sul, Porto Alegre, 1992.

QUADROS, F.L.F.; MARASCHIN, G.E. Desempenho animal em misturas de espécies forrageiras de estação fria. Pesquisa Agropecuária Brasileira, v.22, n.5, p.535-541, 1987.

REAL, D. Estado actual y futuro de la producción y utilización de leguminosas forrajeras en la zona Campos. In: Reunión de Grupo
Técnico en Forrajeras del Cono Sul - Zona Campos, 14., 2002, Mercedes. Anais... Mercedes: INTA, 2002. p.78-82.

SANTOS, I.P.A.; LIMA, M.L.P.; BERCHIELLI, T.T. et al. Influência do fósforo, micorriza e nitrogênio no conteúdo de minerais de Brachiaria brizanta e Arachis pintoi consorciados. Revista Brasileira de Zootecnia, v.31, n.2, p.605-616, 2002.

SCHEFFER-BASSO, S.M.; VENDRUSCULO, M.C.; CECCHETTI, D. Desempenho de leguminosas nativas (Adesmia) e exóticas (Lotus, Trifolium), em função do estádio fenológico no primeiro corte. Revista Brasileira de Zootecnia, v.34, n.6, p.1871-1880, 2005. SOARES, J.P.G.; BERCHIELLI, T.T.; AROEIRA, L.J.M. et al. Estimativas de consumo do capim-elefante (Pennisetum purpureum Schum.), fornecido picado para vacas lactantes utilizando a técnica do óxido crômico. Revista Brasileira de Zootecnia, v.33, n.3, p.811-820, 2004.

SOBCZAK, M.F.; OLIVO, C.J.; GABBI, A.M. et al. [2005]. Evaluation of an elephantgrass pasture mixed with black oat managed under agro ecological principles in winter period. Livestock Research for Rural Development, v.17, n.6, 2005. Disponível em: <http://www.cipav.org.co/lrrd/lrrd17/6/fati17071.htm> Acesso em: 10/2/2006.

SOCIEDADE BRASILEIRA DE CIÊNCIA DO SOLO - SBCS. Manual de adubação e calagem para os estados do Rio Grande do Sul e Santa Catarina. Porto Alegre: 2004. 394p.

STATISTICAL ANALYSIS SYSTEM - SAS. User's guide: statistics Version 6.12, Cary: SAS Institute, 1997. (CD-ROM).

STOBBS, T.H. The effect of plant structure on the intake of tropical pasture. 2. Differences in sward structure, nutritive value, and bite size of animals grazing Setaria anceps and Chloris gayana at various stages of growth. Australian Journal of Agricultural Research, v.24, n.6, p.821-829, 1973.

TILLEY, J.M. A.; TERRY, R.A. A two-stage technique of the "in vitro" digestion of forage crop. Journal of the British Grassland Society, v.18, n.2, p.104-111, 1963.

TOWNSEND, C.R.; OLIVO, C.J.; RUVIARO, C.F. Desempenho de novilhas da raça Holandesa em cultivares de capim-elefante (Pennisetum purpureum Schum.). Ciência Rural, v.24, n.2, p.381-386, 1994.

VALENTIM, J.F.; ANDRADE, C.M.S.; MENDONÇA, H.A. et al. Velocidade de estabelecimento de acessos de amendoim forrageiro na Amazônia Ocidental. Revista Brasileira de Zootecnia, v.32, n.6, p.1569-1577, 2003.

Van SOEST, P.J.; ROBERTSON. J.B.; LEWIS, B.A. Methods for dietary fiber, neutral detergent fiber, and nonstarch polysaccharides in relation to animal nutrition. Journal of Dairy Science, v.74, n.1, p.3583-3597, 1991.

VIDOR, M.A.; JAQUES, A.V. Comportamento de uma pastagem sobressemeada com leguminosas de estação fria e avaliada sob condições de corte e pastejo. 1. Disponibilidade de matéria seca, matéria orgânica digestível e proteína bruta. Revista Brasileira de Zootecnia, v.27, n.2, p.267-271, 1998.

WILM, H.G.; COSTELLO, D.F.; KLIPPLE, G.E. Estimating forage yield by the double-sampling methods. Journal American Society Agronomy, n.36, p.194-203, 1944. 